\title{
Additional effect of magnesium sulfate and vitamin $C$ in laparoscopic gynecologic surgery for postoperative pain management: a double-blind randomized controlled trial
}

\section{Sungho Moon', Sehun Lim', Jongwon Yun', Wonjin Lee ${ }^{1,2}$, Myounghun Kim ', Kwangrae Cho', and Seunghee Ki ${ }^{1}$}

Received May 20, 2019

Revised August 7, 2019

Accepted August 7, 2019

\section{Corresponding author}

Sehun Lim, M.D.

Department of Anesthesiology and Pain Medicine, Busan Paik Hospital, Inje University College of Medicine, 75 Bokji-ro, Busanjin-gu, Busan 47392, Korea

Tel: 82-51-890-6520

Fax: 82-51-898-4216

E-mail: anespc@naver.com

\section{ORCID}

https://orcid.org/0000-0001-8450-0595
${ }^{1}$ Department of Anesthesiology and Pain Medicine, Busan Paik Hospital, Inje University College of Medicine, ${ }^{2}$ Paik Institute for Clinical Research, Inje University College of Medicine, Busan, Korea

Background: This clinical trial was conducted to determine whether combined use of magnesium sulfate and vitamin $\mathrm{C}$ more significantly reduced postoperative fentanyl consumption and pain than magnesium sulfate or vitamin $\mathrm{C}$ alone.

Methods: The prospective, double-blinded, randomized controlled study enrolled 132 patients scheduled for laparoscopic gynecologic surgery. The patients were randomly allocated to one of the four groups ( $n=33$ for each group; Group M [magnesium sulfate $40 \mathrm{mg} / \mathrm{kg}$ ], Group V [vitamin C $50 \mathrm{mg} / \mathrm{kg}$ ], Group MV [magnesium sulfate $40 \mathrm{mg} / \mathrm{kg}$ and vitamin C $50 \mathrm{mg} / \mathrm{kg}$ ] and Group C [isotonic saline $40 \mathrm{ml}$ ]). Cumulative postoperative fentanyl consumption (primary endpoint measure), postoperative pain score by numeric rating scale, and postoperative nausea and vomiting were recorded at $1,6,24$, and 48 $\mathrm{h}$ after discharge from the postanesthesia care unit.

Results: Cumulative postoperative fentanyl consumption was significantly less in Groups M, V, and MV than in Group C at all time points. Group MV showed significantly less cumulative postoperative fentanyl consumption than Group M at postoperative $24 \mathrm{~h}$ (mean \pm standard deviation, $156.6 \pm 67.5$ vs. $235.6 \pm 94.6 \mu \mathrm{g}, \mathrm{P}=0.001$ ), as well as significantly less consumption than Groups $\mathrm{M}$ and $\mathrm{V}$ at postoperative $48 \mathrm{~h}$ (190.8 $\pm 74.6 \mathrm{vs}$. $301.0 \pm 114.8$ or $284.1 \pm 128.6 \mu g, P<0.001, P=0.003$, respectively).

Conclusions: Combined use of magnesium sulfate and vitamin $\mathrm{C}$ provides an additional benefit in postoperative pain management after laparoscopic gynecologic surgery in comparison to single administration of magnesium sulfate or vitamin C.

Keywords: Ascorbic acid; Laparoscopy; Magnesium sulfate; N-Methyl-D-Aspartate receptors; Postoperative pain.

\section{INTRODUCTION}

Postoperative pain, despite advances in pain management, remains an important clinical problem. Inadequate postoperative analgesia can lead not only to serious clinical prob- lems but also to diminished quality of life and patient satisfaction $[1,2]$. Opioids provide potent analgesia for patients with moderate to severe pain and remain the mainstay of postoperative pain analgesia, but these substances also have multiple adverse effects (e.g., nausea, vomiting, impaired gas-

This is an Open Access article distributed under the terms of the Creative Commons Attribution Non-Commercial License (http://creativecommons.org/licenses/by-nc/4.0) which permits unrestricted non-commercial use, distribution, and reproduction in any medium, provided the original work is properly cited.

Copyright (c) the Korean Society of Anesthesiologists, 2020 
trointestinal motility, and respiratory depression) [1]. These adverse effects are dose-dependent and have considerable inter-individual variability [3]. To improve the analgesic effect and reduce these adverse effects, several co-analgesic agents and interventions have been introduced [4].

Magnesium is a divalent cation that plays a key role in ATPase activities in physiologic processes. It is an antagonist of N-methyl-D-aspartate (NMDA) receptors in the central nervous system and attenuates central sensitization [5,6].

Vitamin C (ascorbic acid) is a water-soluble vitamin and an antioxidant that is necessary for growth and development. It is also known for neuroprotective and neuromodulating effects $[7,8]$. The exact analgesic mechanism of vitamin $\mathrm{C}$ is unknown, and multiple functions of the vitamin may be involved in that process.

Several clinical studies have reported that perioperative administration of magnesium or high-dose vitamin C can reduce postoperative opioid requirements [5,9]. Some studies compared the analgesic efficacy of magnesium sulfate with that of other drugs [10-12]. Other studies focused on vitamin $\mathrm{C}$ also included some comparisons [13]. The authors of the present study were interested in evaluating the combined efficacy of magnesium sulfate and vitamin $\mathrm{C}$ in reducing acute pain. To our knowledge, this is the first study that compares magnesium sulfate and vitamin $\mathrm{C}$ directly with each other and with the combination of the two.

We investigated the efficacy of the combined use of magnesium sulfate and vitamin $C$ on postoperative pain management by assessing cumulative fentanyl consumption and pain scores for the postoperative $48 \mathrm{~h}$. We hypothesized that a combination of magnesium sulfate and vitamin $\mathrm{C}$ would more significantly reduce cumulative fentanyl consumption than either magnesium sulfate or vitamin $\mathrm{C}$ alone.

\section{MATERIALS AND METHODS}

One hundred thirty-two patients, aged 20 to 60 years, with American Society of Anesthesiologists physical status I or II, who were scheduled for elective laparoscopic gynecologic surgery, were enrolled. This double-blind randomized controlled trial was approved by the Institutional Review Board of our hospital (no. 19-0042), and written, informed consent was obtained for all enrolled patients.

Exclusion criteria were allergy to magnesium sulfate, vita- min C, or any other study drugs; cardiovascular, neuromuscular, renal, or hepatic disease, diabetes, cancer; opioid or analgesic abuse; and treatment with calcium channel blockers. The day before surgery, all enrolled patients were taught how to use the patient-controlled analgesia (PCA) system (AutoMed3400 ${ }^{\circledast}$, Ace Medical, Korea).

Patients were randomly (sealed envelope method) allocated to one of four groups:

1) Magnesium sulfate group (Group M, $\mathrm{n}=33$ ): $40 \mathrm{ml}$ solution of $40 \mathrm{mg} / \mathrm{kg}$ of magnesium sulfate and isotonic saline is injected at a rate of $120 \mathrm{ml} / \mathrm{h}$ for $20 \mathrm{~min}$ as a bolus immediately prior to anesthesia induction. Subsequently, $40 \mathrm{ml}$ of the same solution is infused at a rate of $10 \mathrm{ml} / \mathrm{h}$ by continuous intravenous infusion until the end of the operation (for an infusion of $10 \mathrm{mg} / \mathrm{kg} / \mathrm{h}$ ).

2) Vitamin C group (Group V, $\mathrm{n}=33$ ): $40 \mathrm{ml}$ of a solution of $50 \mathrm{mg} / \mathrm{kg}$ of vitamin C (Ascorbic Acid Injection ${ }^{\circledR}$, Huons Co., Korea) and isotonic saline is injected at a rate of $120 \mathrm{ml} / \mathrm{h}$ for $20 \mathrm{~min}$ as a bolus immediately prior to anesthesia induction. Subsequently, $40 \mathrm{ml}$ of isotonic saline is infused at a rate of 10 $\mathrm{ml} / \mathrm{h}$ by continuous intravenous infusion until the end of the operation.

3) Magnesium sulfate and vitamin C group (Group MV, $\mathrm{n}=$ 33): $40 \mathrm{ml}$ solution of $40 \mathrm{mg} / \mathrm{kg}$ of magnesium sulfate and 50 $\mathrm{mg} / \mathrm{kg}$ of vitamin C with isotonic saline is injected at a rate of $120 \mathrm{ml} / \mathrm{h}$ for $20 \mathrm{~min}$ as a bolus immediately prior to anesthesia induction. Subsequently, $40 \mathrm{ml}$ of a solution of $40 \mathrm{mg} / \mathrm{kg}$ of magnesium sulfate and isotonic saline is infused at a rate of $10 \mathrm{ml} / \mathrm{h}$ by continuous intravenous infusion until the end of the operation.

4) Control group (Group $\mathrm{C}, \mathrm{n}=33$ ): $40 \mathrm{ml}$ of isotonic saline is injected at a rate of $120 \mathrm{ml} / \mathrm{h}$ for $20 \mathrm{~min}$ as a bolus immediately prior to anesthesia induction. Subsequently, $40 \mathrm{ml}$ of isotonic saline is infused at a rate of $10 \mathrm{ml} / \mathrm{h}$ by continuous intravenous infusion until the end of the operation.

Infusion pumps with $50 \mathrm{ml}$ syringes were used in every group. Owing to the yellow color of vitamin C, all syringes were wrapped in aluminum foil. Doses of solutions were based on previous studies $[14,15]$. Solutions were prepared by a pharmacist equipped only with a random assignment table. Data were collected by an anesthesiologist who was blinded to the study groups. Monitoring devices (electrocardiography, non-invasive blood pressure, pulse oximetry, and bispectral index [BIS]) were established. A peripheral nerve stimulator 
(TOF Watch $\mathrm{SX}^{\circledR}$, Organon Ltd., Ireland) was placed on the ulnar nerve on the volar side of the wrist for monitoring of neuromuscular block. Anesthesia was induced with propofol (2 mg/kg), rocuronium (0.6 mg/kg), and remifentanil (4 ng/ $\mathrm{ml}$ ) followed by a target effect site concentration of $2-3 \mathrm{ng} / \mathrm{ml}$ throughout the operation using a target-controlled infusion device (Orchestra ${ }^{\circledR}$ Base Primea, Fresenius Vial, France). Anesthesia was maintained with a $1.0-2.5 \%$ end-tidal concentration of sevoflurane in $50 \%$ oxygen with air to maintain a BIS of 40-60 and appropriate hemodynamic parameters. The magnesium sulfate and anesthetic agent infusions were discontinued at skin closure, and $20 \mu \mathrm{g}$ fentanyl, $30 \mathrm{mg}$ ketorolac, and $0.3 \mathrm{mg}$ ramosetron were administered intravenously. At the point after surgery of TOF ratio $>0.4$, pyridostigmine $0.25 \mathrm{mg} / \mathrm{kg}$ and glycopyrrolate $0.01 \mathrm{mg} / \mathrm{kg}$ were used to antagonize neuromuscular block. The PCA solution contained $15 \mu \mathrm{g} / \mathrm{ml}$ fentanyl in isotonic saline, programmed to administer a bolus dose of $1 \mathrm{ml}$, with a lockout interval of $5 \mathrm{~min}$ and no basal infusion. After the operation, a PCA device was connected to the intravenous line, and patients were transferred to the postanesthesia care unit (PACU). Rescue analgesia
(30 mg ketorolac) was administered at patient request. The anesthesiologist who was blinded to the study group evaluated pain, nausea, vomiting, pruritus, fentanyl consumption, and vital signs every 20 min during patients' stay in the PACU and again at $1,6,24$, and $48 \mathrm{~h}$ after transfer from the PACU to the ward. Duration of surgery and anesthesia, as well as days of hospital stay, were recorded. Pain scores were evaluated using the verbal numeric rating scale (NRS) where $0=$ no pain and $10=$ worst pain intensity. In this study, the primary outcome measure was postoperative cumulative fentanyl consumption and secondary outcome measures were postoperative pain score and the incidence of PONV.

In the pilot study, including 10 patients, $24 \mathrm{~h}$ consumption of fentanyl was mean \pm standard deviation (SD) (378.2 \pm $153.2 \mu \mathrm{g}$ ) for patients undergoing laparoscopic hysterectomy. Based on previous studies, we targeted a $30 \%$ reduction in postoperative fentanyl consumption, and a minimum sample size of 29 patients was required per group with an alpha value of 0.05 and a power of $80 \%[5,15,16]$. Considering $10 \%$ of the rate loss, 33 patients were selected. Statistical analysis was performed using SAS 9.4 (SAS Institute Inc., USA). Differenc-

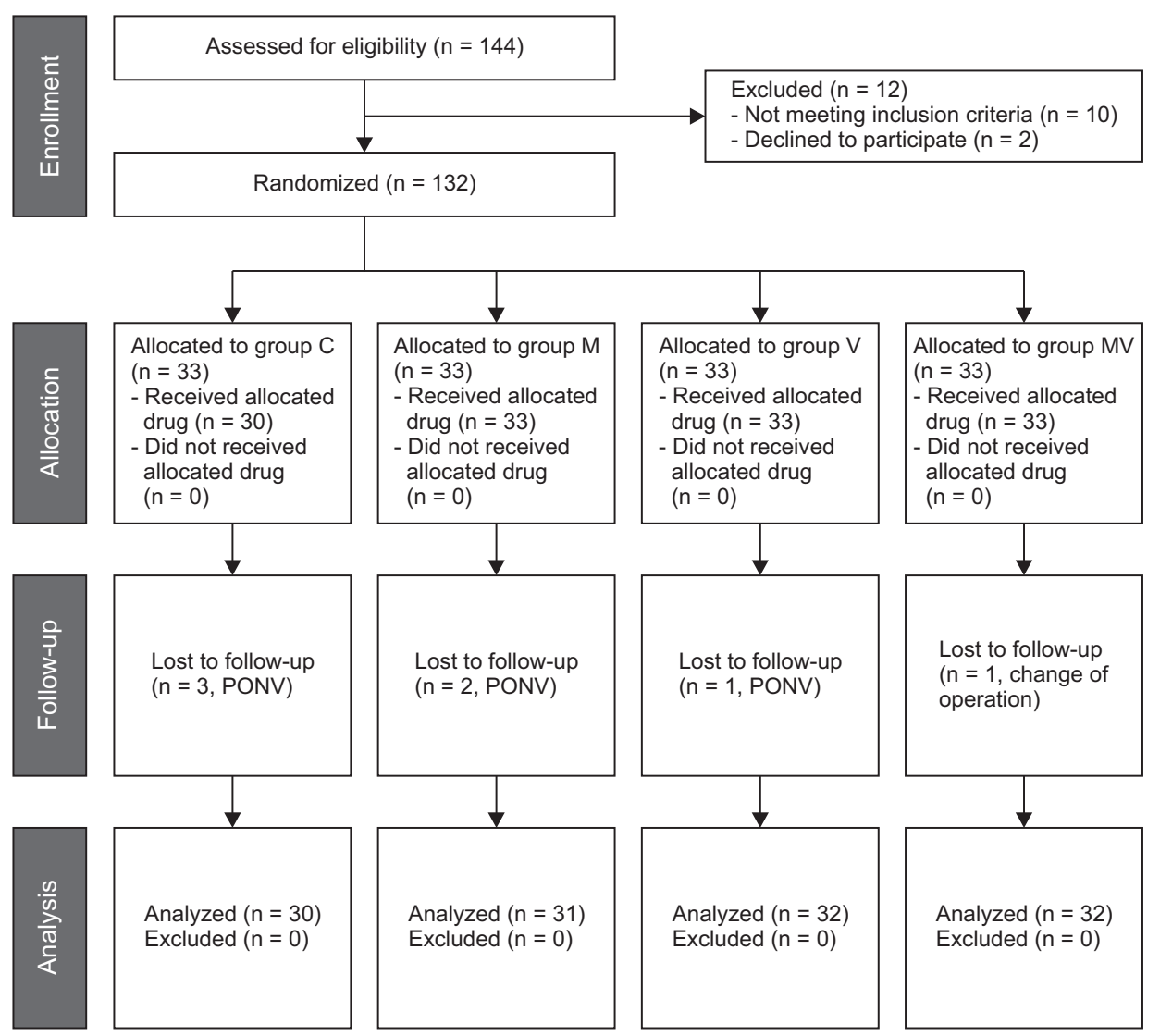

Fig. 1. CONSORT flow diagram. Group C: control group, Group M: magnesium sulfate group, Group V: vitamin C group, Group MV: magnesium sulfate + vitamin C group. PONV: postoperative nausea and vomiting. 
es in American Society of Anesthesiologists physical status, postoperative pain scores (NRS), and incidence of postoperative nausea and vomiting (PONV) were reported as numbers, percentages and were analyzed using the chi-square test or Fisher's exact test. The other continuous variables were analyzed for normality using the Shapiro-Wilk test. Normally distributed parameters were analyzed using analysis of variance (ANOVA), and a post-hoc analysis was performed by Tukey's honestly significant difference (HSD) analysis. If the data did not follow a normal distribution, the Kruskal-Wallis test was used. In cases of a statistical difference $(\mathrm{P}<0.05)$, the MannWhitney test was used for a post-hoc analysis $(\mathrm{P}<0.008)$. All measured data are reported as mean $\pm \mathrm{SD}$, or median with interquartile range $(\mathrm{Q} 1, \mathrm{Q} 3)$ or counts or percentages.

\section{RESULTS}

One hundred thirty-two patients were randomly allocated into groups, and the CONSORT process is illustrated in Fig. 1. After randomized allocation, seven patients were lost to follow-up. Six patients were lost owing to nausea and vomiting, and one owing to a change of the surgical procedure during the operation (Group MV). There were no signs of residual neuromuscular blockade in any subjects. No significant intergroup differences in demographics or other characteristics were present (Table 1).

Cumulative postoperative fentanyl consumption was significantly less in Group M, Group V, and Group MV than in Group C at all times (Fig. 2). In addition, Group MV showed significantly less cumulative postoperative fentanyl consumption than Group M and Group V at certain time points (Group MV, $156.6 \pm 67.5 ; 190.8 \pm 74.6 \mu \mathrm{g}$ compared with Group M, 235.6 \pm 94.6; $301.0 \pm 114.8 \mu \mathrm{g}, \mathrm{P}=0.001, \mathrm{P}<0.001$, at 24 and $48 \mathrm{~h}$ after operation, respectively, compared with Group V, 284.1 \pm 128.6 $\mu \mathrm{g}, \mathrm{P}=0.003,48 \mathrm{~h}$ after operation). Postoperative pain scores at rest at 1, 6, 24, and $48 \mathrm{~h}$ were significantly lower in Group MV (4 [3, 4]; 3 [2, 3]; 2 [1, 2]; and $1.5[1,2])$ than in Group C $(5[4,6] ; 3[3,5] ; 3[2,5]$; and $3[1.75$, 4]; $\mathrm{P}=0.001, \mathrm{P}=0.001, \mathrm{P}<0.001$, and $\mathrm{P}=0.002$, respectively). There was a significant difference in the scores between Group V (4 [3, 4]) and Group C (5 [4, 6]; P = 0.006) at $1 \mathrm{~h}$ postoperatively. In addition, Group MV showed significantly lower NRS than Group M and Group V at $24 \mathrm{~h}$ postoperatively ( $\mathrm{P}<0.001, \mathrm{P}=0.002$, respectively) (Fig. 3). There were no significant difference in postoperative pain scores between

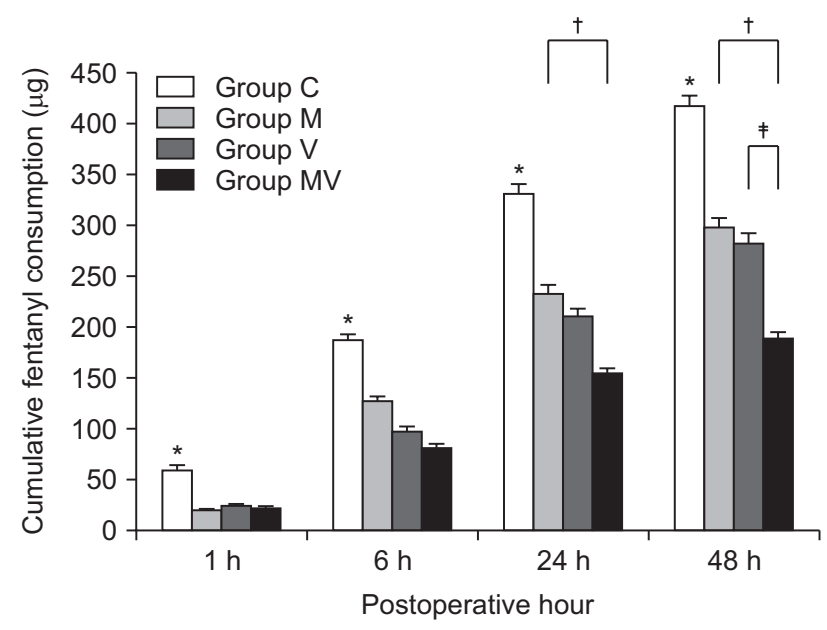

Fig. 2. Cumulative fentanyl consumption. Mean cumulative injected fentanyl dose of the intravenous patient-controlled analgesia solution in the four groups. The error bars show standard deviation. Group C: control group, Group M: magnesium sulfate group, Group V: vitamin C group, Group MV: magnesium sulfate + vitamin C group. *Indicates significant difference between Group $C$ and the other groups $(P<0.008)$. ${ }^{\dagger}$ Indicates significant difference between Group MV and Group M (P = 0.001, $\mathrm{P}<0.001,24$ and $48 \mathrm{~h}$ after operation, respectively). ${ }^{\ddagger}$ Indicates significant difference between Group MV and Group V ( $P=0.003)$.

Table 1. Base of the Characteristics

\begin{tabular}{lcccc}
\hline \multicolumn{1}{c}{ Variable } & Group C $(\mathrm{n}=30)$ & Group M $(\mathrm{n}=31)$ & Group V $(\mathrm{n}=32)$ & Group MV $(\mathrm{n}=32)$ \\
\hline Age $(\mathrm{yr})$ & $41.9 \pm 10.0$ & $40.3 \pm 11.6$ & $40.7 \pm 10.5$ & $38.7 \pm 9.7$ \\
Weight $(\mathrm{kg})$ & $57.6 \pm 8.9$ & $57.4 \pm 7.1$ & $58.4 \pm 10.9$ & $61.9 \pm 10.3$ \\
Height $(\mathrm{cm})$ & $158.4 \pm 4.3$ & $160.8 \pm 6.5$ & $159.6 \pm 5.7$ & $160.7 \pm 5.4$ \\
ASA (I/II) & $25 / 5$ & $21 / 10$ & $26 / 6$ & $27 / 5$ \\
Duration (min) & & & & \\
Surgery & $92.8 \pm 30$ & $79.8 \pm 22.8$ & $18.4 \pm 34.7$ & $80.4 \pm 26.5$ \\
Anesthesia & $128.8 \pm 30.6$ & $115.4 \pm 25.2$ & $3.1 \pm 36.9$ & $114.4 \pm 27.3$ \\
Hospital stay (d) & $3.1 \pm 0.7$ & $3.1 \pm 0.8$ & $3.6 \pm 1.3$ & $3.5 \pm 0.6$ \\
\hline
\end{tabular}

Values are presented as mean \pm SD or number only. Group C: control group, Group M: magnesium sulfate group, Group V: vitamin C group, Group MV: magnesium sulfate + vitamin C group. ASA: American Society of Anesthesiologists physical status. 
Group M and Group V. The incidence of PONV was slightly higher in Group C, especially at 1 and 6 h (12 patients, 40\% and 10 patients, 33\%. 1 and $6 \mathrm{~h}$ after operation, respectively), but the difference was significant only between Group $\mathrm{V}$ and Group $\mathrm{C}(\mathrm{P}=0.001$ and $\mathrm{P}=0.007,1$ and $6 \mathrm{~h}$ after operation, respectively) (Fig. 4). There were no significant intergroup differences in patient requirements for rescue medication in Group C (3), Group M (3), Group V (2), and Group MV (2).

All patients were discharged home without significant complications, and the durations of hospital stays were similar in all groups.

\section{DISCUSSION}

In the present study, both magnesium sulfate and vitamin C significantly reduced fentanyl consumption for postoperative $48 \mathrm{~h}$. Group MV showed significantly less cumulative postoperative fentanyl consumption than Group $\mathrm{M}$ at postoperative $24 \mathrm{~h}$ and than Groups $\mathrm{M}$ and $\mathrm{V}$ at postoperative $48 \mathrm{~h}$.

Magnesium is an important ion that is involved in the regulation of several ion channels and physiologic processes. The exact mechanism of its analgesic effect is not yet clear, but possible key functions are NMDA receptor antagonism

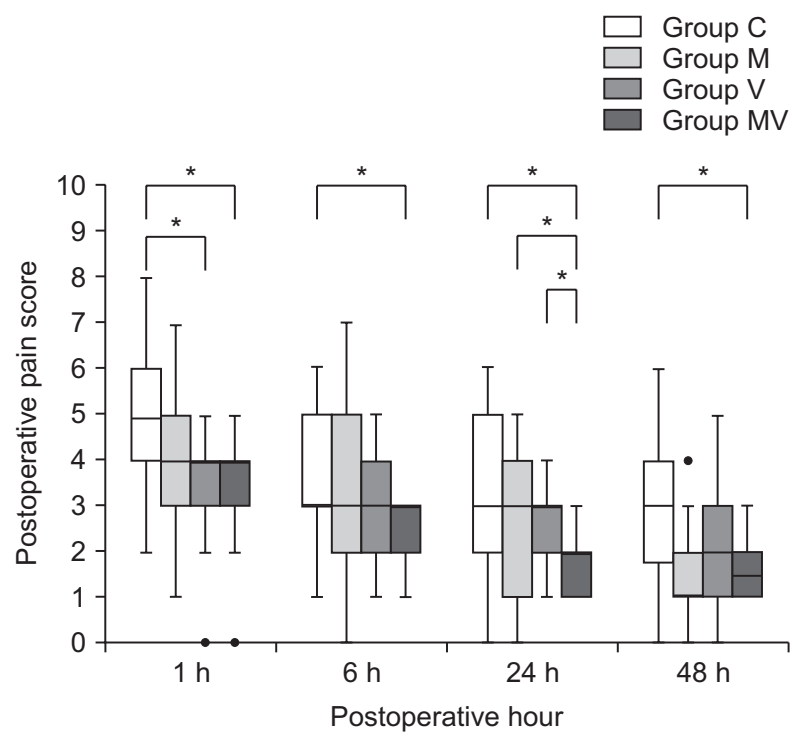

Fig. 3. Postoperative pain scores. Postoperative pain scores by numeric rating scale at 1, 6, 24, $48 \mathrm{~h}$ after surgery. Box plot with median (solid line), interquartile ranges (box) and values within 1.5 interquartile ranges from each side of the box (whiskers). Outliers are indicated by solid circles. Group C: control group, Group M: magnesium group, Group V: vitamin C group, Group MV: magnesium + vitamin C group. *Indicates significant difference between groups $(\mathrm{P}<0.008)$. and inhibition of calcium influx $[17,18]$. Many studies have reported the analgesic efficacy of perioperative intravenous magnesium administration. These studies have suggested several regimens for bolus and infusion [5]. The doses have spanned a fairly wide range, with a bolus dose from 30-50 $\mathrm{mg} / \mathrm{kg}$ followed by an infusion of $6-25 \mathrm{mg} / \mathrm{kg} / \mathrm{h}[5,14]$. Seyhan et al. [14] reported that magnesium $40 \mathrm{mg} / \mathrm{kg}$ as a bolus followed by $10 \mathrm{mg} / \mathrm{kg} / \mathrm{h}$ by continuous infusion leads to a significant reduction in postoperative morphine consumption, compared to other regimens. We also chose this method in the present study owing to our use of the same surgical model ( $40 \mathrm{mg} / \mathrm{kg}$ as a bolus, $10 \mathrm{mg} / \mathrm{kg} / \mathrm{h}$ by infusion).

Oxidative stress and inflammation is associated with arthritis, complex regional pain syndrome, infection, cancer, and surgical trauma [9]. Reactive oxygen species (ROS) mediate neuropathic pain, and ROS scavengers are useful in attenuating mechanical discomfort in a rat model [19]. Vitamin C acts as a potent antioxidant, scavenging both ROS and nitrogen species. Vitamin C also has anti-inflammatory properties, decreasing C-reactive protein and pro-inflammatory cytokines, such as tumor necrosis factor, interferon, and interleukins, which are markers of inflammation [20]. In addition to antioxidative and anti-inflammatory properties, vitamin $\mathrm{C}$ also has a neuromodulating function that has been shown to modulate dopamine and glutamate mediated neurotransmission $[9,21]$. Redox change of the NMDA receptor by

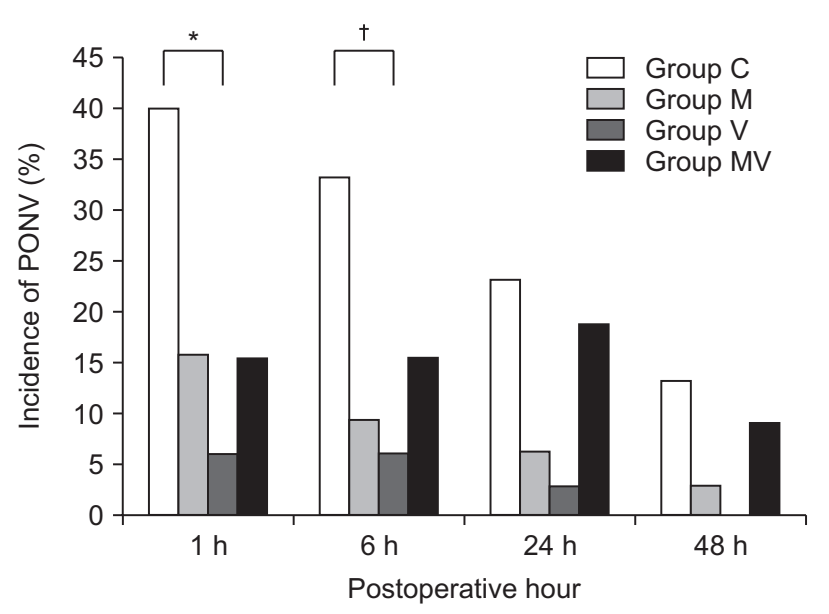

Fig. 4. Incidence of postoperative nausea and vomiting. Values are presented as number (\%). Group C: control group, Group M: magnesium group, Group V: vitamin C group, Group MV: magnesium + vitamin C group, PONV: postoperative nausea and vomiting. *Indicates significant difference between Group C and Group V $(P=0.001) .{ }^{\dagger}$ Indicates significant difference between Group C and Group V ( $P=0.007)$. 
vitamin $\mathrm{C}$ decreases pain in chemical behavioral models of nociception in mice [21]. Vitamin C also acts as a cofactor for the synthesis of catecholamine neurotransmitters, which are known as the inhibitory pain pathway [22]. Based on these studies, vitamin $\mathrm{C}$ has been investigated as a possible adjuvant for postoperative pain management.

Recently, Kanazi et al. [23] used oral vitamin C (2 g) in reducing the postoperative consumption of opioids in patients undergoing laparoscopic cholecystectomy. Jeon et al. [15] used $50 \mathrm{mg} / \mathrm{kg}$ vitamin C by intravenous infusion in a similar attempt to reduce the consumption of opiods following surgery in patients undergoing laparoscopic colectomy. Ayatollahi et al. [24] showed that administration of vitamin C (3 g) by intravenous infusion reduced postoperative pain without increased side effects in patients undergoing uvulopalatopharyngoplasty and tonsillectomy. At a dose of $500 \mathrm{mg}$, approximately $63 \%$ of oral vitamin $\mathrm{C}$ is absorbed, compared to absorption of $46 \%$ of a dose of 1,250 mg, and steady state plasma vitamin C concentrations rarely exceed $80 \mu \mathrm{M}$ because of rapid renal clearance $[25,26]$. In addition, osmotic diarrhea has been reported with administration of oral vitamin C over $5 \mathrm{~g}$ [8]. Hence, we chose to administer a dose of $50 \mathrm{mg} /$ $\mathrm{kg}$ vitamin $\mathrm{C}$ by intravenous infusion in the present study.

Numerous studies have examined the perioperative use of magnesium sulfate and vitamin $C$ for pain management; these have shown the suppression of neuropathic pain $[5,9,13]$ and the potentiation of opioid analgesia $[15,17,23]$. According to the previous studies, perioperative magnesium sulfate and vitamin C are relatively safe to use without any reported serious side effects. Moreover, there are many cases of using vitamins with other minerals [27].

As in several previous studies, our study showed that magnesium sulfate and vitamin $C$ were effective in reducing postoperative fentanyl requirements [5,9]. Unlike previous studies, we directly compared all groups and used a combination of both magnesium sulfate and vitamin $\mathrm{C}$ as an adjuvant of opioid analgesics. Neither the individual magnesium sulfate nor the vitamin $\mathrm{C}$ group showed a significant difference in reduction of fentanyl consumption. Combined use of the two showed a greater reducing effect than not only the control group, but also than the individual magnesium sulfate and vitamin C groups. Moreover, postoperative pain scores were significantly lower in the combined group than in each of the individual magnesium sulfate and vitamin $\mathrm{C}$ groups at some time points. These outcomes may have shown that combined use of magnesium sulfate and vitamin $\mathrm{C}$ has an additional effect in reducing postoperative fentanyl requirements. In addition, it may be suspected that these two substances act at different NMDA receptor sites, or that they have different sites of analgesic action. The incidence of PONV was slightly higher in Group C than in other groups, especially at 1 and $6 \mathrm{~h}$, but a statistical difference was present only between Group $\mathrm{V}$ and Group C.

There are some limitations in the present study. The incidence of PONV was significantly lower in Group V than in Group $\mathrm{C}$ in the acute postoperative period $(1,6 \mathrm{~h})$, but further studies are needed in this regard. We did not assess the plasma concentration of all groups. The half-life of intravenous vitamin $\mathrm{C}$ (approximately $2 \mathrm{~h}$ ) is very short and there was time for fasting more than eight hours, so additional research on plasma blood concentration appears to be needed. Furthermore, we did not apply equianalgesic doses for the comparison of analgesic efficacy. Some clinical studies have compared magnesium sulfate to ketorolac [10] and fentanyl [28]. In addition, rofecoxib, celecoxib, and acetaminophen have been examined in comparison to vitamin $\mathrm{C}$ following various surgical procedures [13]. However, because there was limited literature regarding direct comparison of analgesic effects between magnesium sulfate and vitamin $C$ in previous studies, we used doses known to be effective based on the previous studies (magnesium sulfate: $40 \mathrm{mg} / \mathrm{kg}$ as a bolus, 10 $\mathrm{mg} / \mathrm{kg} / \mathrm{h}$ of infusion, and vitamin C: $50 \mathrm{mg} / \mathrm{kg}$ ) [9,14]. As described above, since both magnesium sulfate and vitamin C are relatively safe, further experiments examining additional use after surgery may be considered.

In conclusion, this study reports the analgesic efficacy of intravenous magnesium sulfate and vitamin $C$ on postoperative pain management as adjuvant analgesics. In the present study, single use of either magnesium sulfate or vitamin C showed similar reduction of fentanyl consumption in laparoscopic gynecologic surgeries. Moreover, combined use of the two substances significantly reduced postoperative fentanyl consumption and pain scores even in comparison to use of either of the two alone. Therefore, simultaneous infusion of magnesium sulfate and vitamin $\mathrm{C}$ may provide an additional analgesic effect and constitute a useful approach for postoperative pain management. 


\section{CONFLICTS OF INTEREST}

No potential conflict of interest relevant to this article was reported.

\section{ORCID}

Sungho Moon, https://orcid.org/0000-0002-3602-9441

Jongwon Yun, https://orcid.org/0000-0002-7509-8511

Wonjin Lee, https://orcid.org/0000-0002-6240-7370

Myounghun Kim, https://orcid.org/0000-0002-4350-0078

Kwangrae Cho, https://orcid.org/0000-0002-9805-9582

Seunghee Ki, https://orcid.org/0000-0002-1792-3771

\section{REFERENCES}

1. Lovich-Sapola J, Smith CE, Brandt CP. Postoperative pain control. Surg Clin North Am 2015; 95: 301-18.

2. Khan RS, Ahmed K, Blakeway E, Skapinakis P, Nihoyannopoulos L, Macleod K, et al. Catastrophizing: a predictive factor for postoperative pain. Am J Surg 2011; 201: 122-31.

3. Gammaitoni AR, Fine P, Alvarez N, McPherson ML, Bergmark S. Clinical application of opioid equianalgesic data. Clin J Pain 2003; 19: 286-97.

4. Schwenk ES, Mariano ER. Designing the ideal perioperative pain management plan starts with multimodal analgesia. Korean J Anesthesiol 2018; 71: 345-52.

5. Albrecht E, Kirkham KR, Liu SS, Brull R. Peri-operative intravenous administration of magnesium sulphate and postoperative pain: a meta-analysis. Anaesthesia 2013; 68: 79-90.

6. Herroeder S, Schönherr ME, De Hert SG, Hollmann MW. Magnesium--essentials for anesthesiologists. Anesthesiology 2011; 114: 971-93.

7. Rebec GV, Pierce RC. A vitamin as neuromodulator: ascorbate release into the extracellular fluid of the brain regulates dopaminergic and glutamatergic transmission. Prog Neurobiol 1994; 43: 537-65.

8. Fukushima R, Yamazaki E. Vitamin C requirement in surgical patients. Curr Opin Clin Nutr Metab Care 2010; 13: 669-76.

9. Carr AC, McCall C. The role of vitamin C in the treatment of pain: new insights. J Transl Med 2017; 15: 77.

10. Sousa AM, Rosado GM, Neto Jde S, Guimarães GM, Ashmawi HA. Magnesium sulfate improves postoperative analgesia in laparoscopic gynecologic surgeries: a double-blind randomized controlled trial. J Clin Anesth 2016; 34: 379-84.

11. Koltka K, Koknel-Talu G, Asik M, Ozyalcin S. Comparison of efficacy of intraarticular application of magnesium, levobupivacaine and lornoxicam with placebo in arthroscopic surgery. Knee Surg Sports Traumatol Arthrosc 2011; 19: 1884-9.

12. Bolcal C, Iyem H, Sargin M, Mataraci I, Yildirim V, Doganci S, et al. Comparison of magnesium sulfate with opioid and NSAIDs on postoperative pain management after coronary artery bypass surgery. J Cardiothorac Vasc Anesth 2005; 19: 714-8.

13. Chen S, Roffey DM, Dion CA, Arab A, Wai EK. Effect of perioperative vitamin $C$ supplementation on postoperative pain and the incidence of chronic regional pain syndrome: a systematic review and meta-analysis. Clin J Pain 2016; 32: 179-85.

14. Seyhan TO, Tugrul M, Sungur MO, Kayacan S, Telci L, Pembeci $K$, et al. Effects of three different dose regimens of magnesium on propofol requirements, haemodynamic variables and postoperative pain relief in gynaecological surgery. Br J Anaesth 2006; 96: 247-52.

15. Jeon Y, Park JS, Moon S, Yeo J. Effect of intravenous high dose vitamin $\mathrm{C}$ on postoperative pain and morphine use after laparoscopic colectomy: a randomized controlled trial. Pain Res Manag 2016; 2016: 9147279.

16. Turner JA, Turk DC. The significance of clinical significance. Pain $2008 ; 137: 467-8$

17. McCarthy RJ, Kroin JS, Tuman KJ, Penn RD, Ivankovich AD. Antinociceptive potentiation and attenuation of tolerance by intrathecal co-infusion of magnesium sulfate and morphine in rats. Anesth Analg 1998; 86: 830-6.

18. Ma H, Tang J, White PF, Zaentz A, Wender RH, Sloninsky A, et al. Perioperative rofecoxib improves early recovery after outpatient herniorrhaphy. Anesth Analg 2004; 98: 970-5.

19. Kim HK, Park SK, Zhou JL, Taglialatela G, Chung K, Coggeshall $\mathrm{RE}$, et al. Reactive oxygen species (ROS) play an important role in a rat model of neuropathic pain. Pain 2004; 111: 116-24.

20. Mikirova N, Casciari J, Rogers A, Taylor P. Effect of high-dose intravenous vitamin $\mathrm{C}$ on inflammation in cancer patients. J Transl Med 2012; 10: 189.

21. Rosa KA, Gadotti VM, Rosa AO, Rodrigues AL, Calixto JB, Santos AR. Evidence for the involvement of glutamatergic system in the antinociceptive effect of ascorbic acid. Neurosci Lett 2005; 381: 185-8.

22. Harrison FE, May JM. Vitamin C function in the brain: vital role of the ascorbate transporter SVCT2. Free Radic Biol Med 2009; 46: 719-30.

23. Kanazi GE, El-Khatib MF, Yazbeck-Karam VG, Hanna JE, Masri B, Aouad MT. Effect of vitamin C on morphine use after laparoscopic cholecystectomy: a randomized controlled trial. Can J Anaesth 2012; 59: 538-43.

24. Ayatollahi V, Dehghanpour Farashah S, Behdad S, Vaziribozorg S, 
Rabbani Anari M. Effect of intravenous vitamin C on postoperative pain in uvulopalatopharyngoplasty with tonsillectomy. Clin Otolaryngol 2017; 42: 139-43.

25. Levine M, Conry-Cantilena C, Wang Y, Welch RW, Washko PW, Dhariwal KR, et al. Vitamin C pharmacokinetics in healthy volunteers: evidence for a recommended dietary allowance. Proc Natl Acad Sci U S A 1996; 93: 3704-9.

26. Graumlich JF, Ludden TM, Conry-Cantilena C, Cantilena LR Jr, Wang Y, Levine M. Pharmacokinetic model of ascorbic acid in healthy male volunteers during depletion and repletion. Pharm Res 1997; 14: 1133-9.

27. Fritz H, Flower G, Weeks L, Cooley K, Callachan M, McGowan $\mathrm{J}$, et al. Intravenous vitamin $\mathrm{C}$ and cancer: a systematic review. Integr Cancer Ther 2014; 13: 280-300.

28. Khezri MB, Yaghobi S, Hajikhani M, Asefzadeh S. Comparison of postoperative analgesic effect of intrathecal magnesium and fentanyl added to bupivacaine in patients undergoing lower limb orthopedic surgery. Acta Anaesthesiol Taiwan 2012; 50: 19-24. 